\title{
DA PIRÂMIDE À BÚSSOLA: CONSIDERAÇÕES SOBRE O PRINCÍPIO PRO HOMINE E SEU USO NA PROTEÇÃO DOS DIREITOS HUMANOS
}

\author{
Jesus Tupã Silveira Gomes ${ }^{1}$ \\ Gilberto Schäfer ${ }^{2}$
}

\section{RESUMO}

Este estudo examina o princípio pro homine, elemento estruturante do Direito Internacional dos Direitos Humanos, buscando compreender a primazia da norma mais favorável aos sujeitos protegidos. Inicialmente analisamos a pirâmide proposta por Hans Kelsen, indicando sua insuficiência no âmbito dos Direitos Humanos. Em seguida, apontamos construções que conferem status privilegiados a atos normativos infraconstitucionais. Finalmente, exploramos o princípio pro homine, apontando seu caráter primordial na aplicação da norma mais favorável ao indivíduo. O trabalho, elaborado por meio de revisão bibliográfica, indica que o princípio pro homine constitui uma bússola que orienta o jurista na implementação dos direitos humanos.

Palavras-chave: Direito Internacional dos Direitos Humanos - Norma mais favorável Princípio Pro Homine - Pirâmide - Bússola

\section{FROM PYRAMID TO COMPASS: CONSIDERATIONS ON THE PRO HOMINE PRINCIPLE AND ITS USE IN PROTECTING HUMAN RIGHTS}

\begin{abstract}
This paper examines the pro homine principle, the backbone of International Human Rights Law, seeking to understand the primacy of the most favorable standard to the subject. We analyze the pyramid proposed by Hans Kelsen, indicating its insufficiency in the Human Rights scope. We point out constructions that confer privileged status to infra-constitutional normative acts. We explore the pro homine principle, pointing its primary character in the application of the standard more favorable to the individual. The paper, elaborated through literature review, indicates that pro homine principle is a compass that guides the jurist in the implementation of human rights. JESUS TUPÃ SILVEIRA GOMES GILBERTO SCHÄFER
\end{abstract}

Palavras-chave: International Human Rights Law - Most favorable standard - Pro Homine principle - Pyramid - Compass

\footnotetext{
${ }^{1}$ Mestrando em Direitos Humanos - UniRitter. Servidor do Tribunal de Justiça do Estado do Rio Grande do Sul

${ }^{2}$ Doutor em Direito - UFRGS. Juiz de Direito - Tribunal de Justiça do Estado do Rio Grande do Sul
} 


\section{INTRODUÇÃO}

O sistema de proteção aos direitos humanos conta com múltiplas fontes normativas estatais e internacionais que formam uma complexa rede de relações entre entidades internacionais, Estados e indivíduos, cujo objetivo diz respeito ao estabelecimento de um mínimo de proteção à pessoa humana e aos grupos em situação de vulnerabilidade.

A coordenação dessas múltiplas disposições e o estabelecimento de alguma ordem são alcançadas a partir da aplicação do princípio pro homine ou pro persona, elemento estruturante do Direito Internacional dos Direitos Humanos e que implica, em cada caso, a aplicação da norma mais favorável aos sujeitos protegidos.

O objetivo do presente trabalho, elaborado por meio de revisão da bibliografia nacional e estrangeira sobre o tema, consiste em aprofundar o estudo sobre o princípio pro homine, suas funções e suas consequências, buscando compreender a primazia das disposições mais favoráveis aos indivíduos e grupos vulneráveis, como uma bússola de orientação ao operador do Direito, em detrimento da pirâmide normativa proposta por Hans Kelsen.

Para tanto, inicialmente, examinamos a estrutura hierárquica apresentada na Teoria Pura do Direito, atentando para a ausência de um locus específico para os tratados internacionais de direitos humanos e indicando a sua insuficiência para a proteção estabelecida por estes instrumentos. Em seguida, apontamos as diversas construções interpretativas que buscam conferir hierarquia constitucional às disposições normativas que lhe são inferiores, pretendendo conferir-lhe status privilegiado nos ordenamentos jurídicos estatais. Por derradeiro, analisamos o princípio pro homine em suas duas vertentes, interpretativa e normativa, reconhecendo seu caráter primordial na busca e aplicação da norma mais favorável aos indivíduos e grupos em situação de vulnerabilidade.

Os estudos realizados indicam que não há critérios a priori para a indicação dos atos normativos que conferem maior proteção à pessoa humana. Cada caso exige uma análise detalhada dos fatos e dos ordenamentos jurídicos nacional e internacional. Assim, desde que adequadamente compreendido, o princípio pro homine constitui uma espécie de guia - uma bússola - que orienta o operador do Direito na realização dos fins e objetivos que orientam todo o sistema de proteção aos direitos humanos. 


\section{A PIRÂMIDE DE KELSEN E A RIGIDEZ DA HIERARQUIA NORMATIVA}

Uma das primeiras lições apresentadas a qualquer estudante de Direito é a de que o sistema jurídico positivo apresenta uma ordem, em que cada ato normativo encontra seu fundamento de validade em uma disposição que lhe é superior, partindo da regra mais concreta para aquela mais abstrata (KELSEN, 1998). Forma-se, assim, uma pirâmide que possui, em sua base, as sentenças judiciais ${ }^{3}$, os contratos e os atos administrativos de efeitos concretos. Logo acima, estão as leis - aqui tomadas em seu sentido amplo, enquanto atos normativos de natureza geral - e os costumes. Seguindo adiante, encontram-se as emendas constitucionais e, acima destas, está a Constituição ${ }^{4}$. Conforme aponta Losano, “a estrutura hierárquica do ordenamento jurídico é concebida como uma rede capilar para a distribuição do dever ser das normas de grau superior às de grau inferior" (2010, p. 110).

Essa estrutura escalonada, fundada no postulado da supremacia da Constituição, permite a imediata identificação da posição ocupada, no ordenamento jurídico, por qualquer ato normativo, bem como a aferição de sua compatibilidade formal e material com as disposições que lhe são superiores, possibilitando o exercício dos controles de constitucionalidade e de legalidade (BARROSO, 2010). Constitui-se, assim, um parâmetro estático, em que cada dispositivo encontra um local específico e imutável, tendo em vista tão somente o momento de sua criação.

Cumpre destacar que essa pirâmide foi concebida para a aferição da validade dos atos normativos criados em um determinado Estado (KELSEN, 1998), sem que tenha sido estabelecida uma posição hierárquica específica para os tratados internacionais de Direitos Humanos. Cumpre referir que, para Kelsen (1998), cada Estado encontra-se submetido ao ordenamento jurídico internacional, segundo uma perspectiva monista, de integração entre as ordens externa e interna, com prevalência do Direito Internacional. Aponta o autor:

\footnotetext{
${ }^{3}$ Pode-se questionar o locus atribuído por Hans Kelsen aos atos judiciais, tendo em vista que nem sempre o julgamento proferido pelo Poder Judiciário resolve uma questão concreta entre particulares ou entre estes e o Estado. Nesse sentido, as decisões do Supremo Tribunal Federal - no exercício da jurisdição constitucional e na edição de súmulas vinculantes - e do Superior Tribunal de Justiça - ao examinar Recursos Especiais submetidos ao regime das demandas repetitivas, estabelecendo precedentes vinculantes aos demais juízes, conforme previsto no artigo 927, inciso III, do Código de Processo Civil - levam à criação de regras gerais, aproximando-se da atividade legislativa (SCHÄFER, 2012), e devem ocupar posição equivalente aos atos normativos a que se referem. ${ }^{4}$ A discussão sobre a natureza da norma jurídica fundamental pressuposta, apontada por Kelsen como fundamento de validade da Constituição, ultrapassa os limites do presente estudo, razão pela qual não será objeto de exame mais detalhado.
} 
“O Estado como órgão do Direito internacional” - esta é a única expressão metafórica do fato de que a ordem jurídica de cada Estado, de que cada ordem jurídica nacional, está organicamente ligada à ordem jurídica internacional e, através dessa ordem, a todas as outras ordens jurídicas nacionais, de modo que todas as ordens jurídicas se fundem num sistema jurídico integrado. (KELSEN, 2000, p. 504).

Essa "suposta" omissão ensejou um intenso debate doutrinário sobre a posição hierárquica que deve ser atribuída aos tratados internacionais de Direitos Humanos em cada Estado. Com efeito, ainda que a Convenção de Viena sobre o Direito dos Tratados disponha, em seu artigo 27, que "Uma parte não pode invocar as disposições de seu direito interno para justificar o inadimplemento de um tratado.” (BRASIL, 2009), não há um comando explícito para que as normas convencionais sejam incorporadas aos ordenamentos jurídicos estatais em uma determinada hierarquia: o que existe é a possibilidade de responsabilização, no plano internacional, daquele Estado que venha a descumprir as obrigações assumidas.

Para citar apenas o contexto latino-americano, observa-se que as Constituições da Colômbia (artigo 93.2 $2^{5}$ ) e da Guatemala (artigo 46 ${ }^{6}$ ) estabelecem, de forma expressa, que as disposições convencionais prevalecem sobre os dispositivos constitucionais. De outra parte, as

\footnotetext{
5 “Articulo 93. (...) 2. Los derechos y deberes consagrados en esta Carta, se interpretarán de conformidad con los tratados internacionales sobre derechos humanos ratificados por Colombia." (“Artigo 93. (...) 2. Os tratados e convenções internacionais ratificados pelo Congresso, que reconhecem os direitos humanos e que proíbem sua limitação nos estados de exceção prevalecem na ordem interna. Os direitos e deveres consagrados nesta Corte serão interpretados em conformidade com os tratados internacionais de direitos humanos ratificados pela Colômbia - tradução nossa).

6 "Articulo 46 - Preeminencia del Derecho Internacional. Se establece el principio general de que en materia de derechos humanos, los tratados y convenciones aceptados y ratificados por Guatemala, tienen preeminencia sobre el derecho interno." (Artigo 46 - Primazia do Direito Internacional. Estabelece-se o princípio geral de que, em matéria de direitos humanos, os tratados e convenções aceitos e ratificados pela Guatemala têm primazia sobre o direito interno - tradução nossa).
} 


\section{DA PIRÂMIDE À BÚSSOLA: CONSIDERAÇÕES SOBRE O PRINCÍPIO PRO HOMINE E SEU USO NA PROTEÇÃO DOS DIREITOS HUMANOS}

\section{Constituições da Argentina (artigo 75.2277) e do México (artigo 1.2 ${ }^{8}$ ) atribuíram hierarquia} constitucional aos tratados internacionais de direitos humanos. Por sua vez, as Constituições do Uruguai $^{9}$ e do Peru ${ }^{10}$ não indicam de forma expressa, em qualquer dispositivo, o grau hierárquico atribuído aos tratados internacionais de direitos humanos.

Em idêntico sentido, a Constituição brasileira não dispunha, em sua redação original, sobre a hierarquia dos tratados internacionais incorporados ao nosso ordenamento jurídico, apesar de o artigo $5^{\circ}, \S 2^{\circ}$, admitir a existência de direitos fundamentais previstos em tratados internacionais de que o Brasil fosse parte (BRASIL, 1988). Esse fato gerou intenso debate acadêmico, conforme aponta Ramos (2014). Cumpre destacar que a Emenda Constitucional n. 45/2004, ao inserir o $\S 3^{\circ}$ no artigo $5^{\circ}$ da Constituição Federal (“Os tratados e convenções

\footnotetext{
7“Art. 75. Compete al Congresso: (...) 22. Aprobar o desechar tratados concluidos con las demás naciones y con las organizaciones internacionales y los concordatos con la Santa Sede. Los tratados y concordatos tienen jerarquía superior a las leyes. La Declaración Americana de los Derechos y Deberes del Hombre; la Declaración Universal de Derechos Humanos; la Convención Americana sobre Derechos Humanos; el Pacto Internacional de Derechos Económicos, Sociales y Culturales; el Pacto Internacional de Derechos Civiles y Políticos y su Protocolo Facultativo; la Convención sobre la Prevención y la Sanción del Delito de Genocidio; la Convención Internacional sobre la Eliminación de todas las Formas de Discriminación Racial; la Convención sobre la Eliminación de todas las Formas de Discriminación contra la Mujer; la Convención contra la Tortura y otros Tratos o Penas Crueles, Inhumanos o Degradantes; la Convención sobre los Derechos del Niño; en las condiciones de su vigencia, tienen jerarquía constitucional, no derogan artículo alguno de la primera parte de esta Constitución y deben entenderse complementarios de los derechos y garantías por ella reconocidos. Sólo podrán ser denunciados, en su caso, por el Poder Ejecutivo Nacional, previa aprobación de las dos terceras partes de la totalidad de los miembros de cada Cámara. Los demás tratados y convenciones sobre derechos humanos, luego de ser aprobados por el Congreso, requerirán del voto de las dos terceras partes de la totalidad de los miembros de cada Cámara para gozar de la jerarquía constitucional." (Art. 75. Compete ao Congresso: (...) 22. Aprovar ou rejeitar tratados celebrados com as demais nações e com as organizações internacionais e com a Santa Sé. Os tratados e convenções têm hierarquia superior às leis. A Declaração Americana dos Direitos e Deveres do Homem; a Declaração Universal dos Direitos Humanos; a Convenção Americana de Direitos Humanos, o Pacto Internacional de Direitos Econômicos, Sociais e Culturais; o Pacto Internacional dos Direitos Civis e Políticos e seu Protocolo Facultativo; a Convenção para a Prevenção e a Punição do Delito de Genocídio; a Convenção sobre a Eliminação de todas as Formas de Discriminação contra a Mulher, a Convenção contra a Tortura e outros Tratamentos ou Penas Cruéis, Desumanas ou Degradantes; a Convenção sobre os Direitos da Criança; em suas condições de vigência, têm hierarquia constitucional, não derrogam qualquer artigo da primeira parte desta Constituição e devem ser compreendidos como complementares aos direitos e garantidos por ela reconhecidos. Somente poderão ser denunciados pelo Poder Executivo Nacional com prévia aprovação de dois terços da totalidade dos membros de cada Câmara. Os demais tratados e convenções sobre direitos humanos, após aprovados pelo Congresso, necessitarão do voto de dois terços da totalidade dos membros de cada Câmara para gozar da hierarquia constitucional. - tradução nossa).

8 "Artículo $1^{\circ}$. (...) Las normas relativas a los derechos humanos se interpretarán de conformidad con esta Constitución y con los tratados internacionales de la materia favoreciendo en todo tiempo a las personas la protección más amplia." (Artigo $1^{\circ}$. (...) As normas relativas a direitos humanos serão interpretadas em conformidade com esta Constituição e com os tratados internacionais sobre a matéria favorecendo a proteção mais ampla às pessoas. - tradução nossa).

${ }^{9}$ Em seu artigo 168.20, a Constituição Uruguaia limitou-se a atribuir ao Presidente da República a competência para celebrar tratados internacionais, mostrando-se necessária, para sua ratificação, a aprovação pelo Poder Legislativo.

${ }^{10}$ A Constituição Peruana, em seu artigo 55, dispõe apenas que os tratados celebrados pelo Estado e que se encontram em vigor fazem parte do direito nacional, sendo exigida, na forma do artigo 56, a aprovação pelo Congresso, no caso de tratados sobre Direitos Humanos (PERU, 1993).
} 
internacionais sobre direitos humanos que forem aprovados, em cada Casa do Congresso Nacional, em dois turnos, por três quintos dos votos dos respectivos membros, serão equivalentes às emendas constitucionais.") não teve o efeito de encerrar as discussões sobre o posicionamento dos tratados internacionais de direitos humanos no ordenamento jurídico pátrio.

Nos dias atuais, o Supremo Tribunal Federal atribuiu hierarquia supralegal aos tratados internacionais de direitos humanos, conforme a posição firmada no julgamento do RE $\mathrm{n}$. 466.343/SP, em que se abordou a questão da prisão civil do depositário infiel. Por maioria de 6 a 5, a Corte acolheu a tese defendida pelo Min. Gilmar Mendes, segundo a qual os dispositivos inscritos nos tratados internacionais de direitos humanos, ao serem incorporados ao ordenamento jurídico brasileiro, assumem posição intermediária entre a Constituição e os atos normativos em sentido lato. Assim, apesar de não gozarem do status normativo atribuído aos dispositivos constitucionais, os tratados internacionais de direitos humanos afastam a incidência das disposições infraconstitucionais que lhe sejam contrárias (BRASIL, 2008).

Mazzuoli (2016) e Ramos (2014), dentre outros, atribuem caráter materialmente constitucional aos tratados internacionais de direitos humanos incorporados ao Direito brasileiro, com fundamento no artigo $5^{\circ}, \S 2^{\circ}$, da Constituição Federal, o qual é interpretado como uma cláusula de abertura do ordenamento jurídico interno às disposições convencionais. De tal sorte, independentemente do procedimento estabelecido no artigo $5^{\circ}, \S 3^{\circ}$, da Constituição Federal (o qual é necessário tão somente para conferir às disposições convencionais caráter formalmente constitucional), os dispositivos inscritos nos tratados internacionais de Direitos Humanos passam a ter, sempre, status materialmente constitucional.

Dessa forma, os atos normativos infraconstitucionais encontram-se sujeitos a um sistema de duplo controle: o primeiro, de caráter material e formal, perante a Constituição Federal ou Estadual, a ser realizado pelo Supremo Tribunal Federal ou pelos Tribunais de Justiça (em se tratando de controle concentrado de constitucionalidade) ou pelos diversos órgãos que compõem o Poder Judiciário (em sede de controle de constitucionalidade difuso); o segundo, de caráter material, tendo como parâmetro os tratados internacionais de direitos humanos celebrados e ratificados pelo Brasil e que estejam em vigor no plano interno, a ser realizado pelos juízes nacionais ou pela Corte Interamericana de Direito Humanos. Nas palavras de Mazzuoli (2016, p. 211-212): 
Do sistema do domestic affair (em que a tutela dos direitos competia exclusivamente aos juízes nacionais) passamos para o sistema do international concern (segundo o qual, se os juízes nacionais não tutelam um determinado direito, este pode e deve ser tutelado pelos juízes internacionais). (grifos no original).

Em consequência, não há mais falar em um apego exclusivo à hierarquia normativa, especialmente no que se refere às disposições relativas aos direitos humanos, tendo em vista que os tratados internacionais de direitos humanos impõem aos Estados uma ampliação do espectro de proteção das pessoas e dos grupos em situação de vulnerabilidade (APPIO, 2013).

\section{A FLEXIBILIZAÇÃO DA ESTRUTURA HIERÁRQUICA QUANTO AOS DIREITOS HUMANOS}

A estrutura hierárquica piramidal proposta por Kelsen leva em conta tão somente o momento de formação dos atos normativos que compõem o ordenamento jurídico (GUASTINI, 2011). Em consequência, ela não se mostra suficiente para descrever as disposições relativas aos direitos fundamentais e aos direitos humanos, em que a hierarquia estabelecida possui natureza essencialmente material.

Com efeito, ao tratar dos direitos fundamentais, a Constituição Federal fixou limites mínimos de proteção do indivíduo frente ao Estado e aos demais atores sociais, formando um sistema aberto, flexível e capaz de absorver novos conteúdos (SARLET, 2012), como forma de concretização da dignidade da pessoa humana - fundamento do Estado brasileiro.

Além disso, as disposições que definem direitos fundamentais não se esgotam na declaração contida em um determinado enunciado normativo. Elas são fruto da interpretação, da atribuição de significados e da influência dos valores admitidos pelo ordenamento, podendo ou não estar inscritas diretamente no texto da Constituição Federal, fenômeno que possibilita a existência de norma de direito fundamental atribuída, nas palavras de Alexy (2015).

Em idêntico sentido, Sarlet (2015) defende a existência de direitos fundamentais instituídos por meio da legislação ordinária, desde que eles possam ser deduzidos diretamente da Constituição, razão pela qual esses dispositivos apresentam caráter materialmente constitucional.

Por sua vez, os diversos enunciados que estabelecem direitos fundamentais atribuem posições jurídicas aos indivíduos e coletividades, o que lhes possibilita exigir do Estado (e de outros particulares) as proteções que lhes foram outorgadas impondo-se a este(s) o seu cumprimento ou, pelo menos, a não intervenção na esfera de atuação privada, caracterizando o

Rev. de Direitos Humanos em Perspectiva | e-ISSN: 2526-0197 | Maranhão | v. 3 | n. 2 | p. 22 - 38 | 
pode ser denominado norma de direito fundamental completo, ou seja, "um feixe de posições definitivas e prima facie, relacionadas entre si por meio das três formas apresentadas [relações de especificação, de meio-fim e de sopesamento] e que são atribuídas a uma disposição de direito fundamental" (ALEXY, 2015, p. 252).

Deve-se destacar, igualmente, o conceito de bloco de constitucionalidade formulado por Favoreu, formado pelo conjunto de disposições existentes no ordenamento jurídico francês que possuem caráter materialmente constitucional sem estar expressamente inscrito na Constituição de 1958: a Declaração Universal dos Direitos Homem e do Cidadão de 1789, o Preâmbulo da Constituição de 1946 e os princípios fundamentais reconhecidos pelas leis da República (FAVOREU; LLORENTE, 1991).

Em debate estabelecido com Francisco Rubio Llorente, o autor francês declarou expressamente que o bloco de constitucionalidade constitui o parâmetro a ser utilizado pelo juiz constitucional ao examinar uma determinada questão, variando seu conteúdo conforme o caso concreto (FAVOREU; LLORENTE, 1991). Ademais, Favoreu afirma expressamente que os tratados internacionais não integram o bloco de constitucionalidade porque não cumpre ao Conselho Constitucional francês examinar a compatibilidade entre os atos normativos internos e os tratados internacionais eventualmente celebrados por aquele país

Evidentemente, o conteúdo do bloco de constitucionalidade sofreu alterações ao longo do tempo e também ao ingressar no ordenamento jurídico brasileiro, podendo ser atualmente descrita, como “... a somatória daquilo que se adiciona à Constituição escrita, em função dos valores e princípios nela consagrados.", na feliz expressão de LAFER (2005), mostrando-se possível que disposições inscritas em atos normativos de natureza infraconstitucional possam servir de parâmetro para o próprio controle de constitucionalidade de outros dispositivos.

Os diversos instrumentos acima apontados possibilitam uma certa mobilidade na hierarquia normativa, autorizando que uma determinada disposição possa ser alçada a um nível superior pelo operador do Direito na busca da maior realização do princípio da dignidade da pessoa humana, afastando a incidência de dispositivos aparentemente contraditórios, o que não implica sua revogação nem impede sua aplicação sobre um suporte fático diverso. Estabelecese um verdadeiro diálogo entre as diversas fontes normativas, a partir da valorização dos direitos humanos (MIRAGEM, 2012).

Em vez de uma análise a priori, de caráter puramente abstrato, a interpretação e a integração dos diversos atos normativos vigentes no ordenamento jurídico, sejam eles de 
natureza constitucional, legal, judicial ou contratual, dependem do exame do caso concreto, tendo como finalidade última a proteção da pessoa humana. Pode-se falar, conforme aponta Guastini (2011), na formulação de uma hierarquia axiológica, segundo a qual o intérprete atribui, segundo um critério de comparação seu, valor superior a uma determinada disposição normativa em relação a outro enunciado.

No entanto, não há discricionariedade pura e simples do julgador: ele encontra-se vinculado ao ordenamento jurídico como um todo, devendo aplicar, em cada caso concreto, os valores e princípios preponderantes para aquela situação específica, justificando seu posicionamento, o que possibilita aos demais intérpretes o controle do ato realizado (LOURENÇO, 2012).

Não se pode olvidar, nesse sentido, que o bem comum internacional e regional encontra-se em um nível axiológico superior aos interesses nacionais (SAGÜÉS, 2010), razão pela qual os tratados internacionais de direitos humanos devem gozar de preponderância na ordem jurídica interna, independentemente da posição hierárquica que lhe foi atribuída por cada Estado, conforme passamos a examinar no próximo tópico.

\section{O PRINCÍPIO PRO HOMINE E A APLICAÇÃO DA NORMA MAIS FAVORÁVEL}

O princípio pro homine - também denominado pro persona ou favor persona pelos autores de língua espanhola, por constituírem termos neutros em relação ao gênero (CASTAÑEDA, 2015; MEDELlíN URQUiAGA, 2013; AGUILAR CAVALlO; NOGUEIRA ALCALÁ, 2016) - constitui a espinha dorsal do sistema internacional de proteção dos direitos humanos, decorrente do esforço dos diversos Estados, após o encerramento da Segunda Guerra Mundial, em estabelecer um mínimo de proteção à pessoa humana, de forma a impedir a repetição das atrocidades ocorridas na Europa (MAZZUOLI; RIBEIRO, 2016).

Trata-se de uma norma originária do Direito Internacional dos Direitos Humanos que possibilita a coordenação das diversas fontes normativas existentes no âmbito internacional, exigindo do operador do Direito que se atribua, em cada caso, a maior proteção à suposta vítima de violação dos direitos humanos (TRINDADE, 2010).

O referido princípio pode assumir o caráter de vetor de interpretação para uma determinada disposição normativa, direcionando a atuação do intérprete para os significados que possibilitem o maior espectro de proteção à pessoa humana, ou venham a restringir em

Rev. de Direitos Humanos em Perspectiva | e-ISSN: 2526-0197 | Maranhão | v. 3 | n. 2 | p. 22 - 38| 
menor grau seu âmbito de atuação (MEDELLÍN URQUIAGA, 2013), ou pode atuar como um instrumento auxiliar na escolha do dispositivo legal aplicável a um determinado caso (CASTAÑEDA, 2015).

A aplicação do princípio pro homine, porém, não se encontra limitada ao âmbito internacional, o que possibilita ao operador do Direito examinar, de forma conjunta, as disposições convencionais e os dispositivos inscritos em um determinado ordenamento jurídico estatal, sejam eles de caráter material ou processual, buscando o significado que alcance a maior proteção à pessoa Humana (AGUILLAR CAVALLO; NOGUEIRA ALCALÁ, 2016).

Em idêntico sentido, Pinto (1997), leciona que a pluralidade de fontes estatais e internacionais exige do operador do Direito uma compatibilização quanto ao alcance dos direitos protegidos e das obrigações assumidas pelo Estado, a qual deve ser realizada por meio da aplicação do princípio pro homine.

Ele encontra-se expressamente positivado em alguns tratados internacionais de direitos humanos, dentre os quais destacamos os Pactos Internacionais dos Direitos Civis e Políticos (BRASIL, 1992b) e dos Direitos Civis, Econômicos e Sociais (BRASIL, 1992a), cujo artigo 5 - com redação idêntica - assim dispõe:

\begin{abstract}
$\underline{\operatorname{Artigo} 5}$
1. Nenhuma disposição do presente Pacto poderá ser interpretada no sentido de reconhecer a um Estado, grupo ou indivíduo qualquer direito de dedicar-se a quaisquer atividades ou praticar quaisquer atos que tenham por objetivo destruir os direitos ou liberdades reconhecidos no presente Pacto ou impor-lhe limitações mais amplas do que aquelas nele previstas.

2. Não se admitirá qualquer restrição ou suspensão dos direitos humanos fundamentais reconhecidos ou vigentes em qualquer Estado Parte do presente Pacto em virtude de leis, convenções, regulamentos ou costumes, sob pretexto de que o presente Pacto não os reconheça ou os reconheça em menor grau.
\end{abstract}

No âmbito interamericano, sua aplicação decorre da interpretação conferida ao artigo 29 da Convenção Americana de Direitos Humanos - CADH ${ }^{11}$ (BRASIL, 1992,c), o qual determina que sejam adotadas, por um lado, as interpretações que confiram a maior proteção

\footnotetext{
${ }^{11}$ Artigo 29. Normas de interpretação

Nenhuma disposição desta Convenção pode ser interpretada no sentido de:

a. permitir a qualquer dos Estados Partes, grupo ou pessoa, suprimir o gozo e exercício dos direitos e liberdades reconhecidos na Convenção ou limitá-los em maior medida do que a nela prevista;

b. limitar o gozo e exercício de qualquer direito ou liberdade que possam ser reconhecidos de acordo com as leis de qualquer dos Estados Partes ou de acordo com outra convenção em que seja parte um dos referidos Estados; c. excluir outros direitos e garantias que são inerentes ao ser humano ou que decorrem da forma democrática representativa de governo; e

d. excluir ou limitar o efeito que possam produzir a Declaração Americana dos Direitos e Deveres do Homem e outros atos internacionais da mesma natureza.
} 
ao indivíduo ou aos grupos em situação de vulnerabilidade, e, por outro, aquelas mais restritivas no que se refere à limitação das prerrogativas e garantias por ela fixadas.

Conforme apontam Aguilar Cavallo e Nogueira Alcalá (2016), a aplicação do princípio pro homine implica que as disposições normativas relativas aos direitos humanos - nacionais ou internacionais, de caráter material ou processual - devem ser interpretadas extensivamente no que se refere ao reconhecimento de prerrogativas e garantias às supostas vítimas de violação, de forma a garantir-lhes seu efeito útil. Por sua vez, existindo a possibilidade de mais de uma exegese do texto normativo, deve-se optar por aquela que, em maior grau, respeite e garanta o exercício de direitos.

De acordo com Mazzuoli (2010), o princípio pro homine implica uma superação dos critérios tradicionais de superação de antinomias jurídicas - hierárquico, de especialidade e temporal - pelo diálogo entre as diversas fontes normativas, impondo a coordenação entre os diversos dispositivos vigentes nos ordenamentos nacional e internacional. Aponta o referido doutrinador:

O princípio pro homine, em ouras palavras, garante ao ser humano a aplicação da
norma que, no caso concreto, melhor o proteja, levando em conta a força expansiva
dos direitos humanos, o respeito do conteúdo essencial desses direitos e a ponderação
de bens, valores e interesses. Nessa ordem de ideias, faz-se necessário interpretar as
normas domésticas de proteção com aquelas previstas em tratados e declarações
internacionais de direitos humanos, bem assim com a jurisprudência dos organismos
supraestatais de proteção desses direitos, em especial (no caso do Brasil e demais
países do nosso continente) a da Corte Interamericana de Direitos Humanos.
(MAZZUOLI, 2010, p. 107).

Para além da função interpretativa, o princípio pro homine exerce também uma função normativa, estabelecendo uma primazia axiológica que deve ser observada por todos os agentes para a realização dos direitos humanos, possibilitando que, em um determinado caso concreto, seja aplicada uma disposição de hierarquia inferior - por exemplo, uma lei ordinária - em detrimento de outro dispositivo de nível superior (AGUILAR CAVALLO; NOGUEIRA ALCALÁ, 2016).

Retoma-se, aqui, a ideia de hierarquia axiológica proposta por Guastini (2011), tendo em vista que o princípio pro homine estabelece uma preferência prima facie pela interpretação possível que seja mais protetora para o indivíduo no caso concreto (MEDELLÍN URQUIAGA, 2013), a qual já se encontra definida e explicitamente aceita por cada um dos Estados que celebraram os tratados internacionais de direitos humanos. 
Essa primazia axiológica impõe ao operador do Direito o exame das especificidades de cada caso concreto, bem como as disposições normativas estatais e convencionais, para a construção da norma que seja mais protetora ao indivíduo. Conforme esclarece Mazzuoli (2010), não existem critérios fechados ou fórmulas estabelecidas a priori para o estabelecimento das normas aplicáveis a todas as situações de violação aos direitos humanos.

Destaca-se que o julgador, seja ele nacional ou supranacional, não dispõe de poderes para escolher de forma arbitrária os dispositivos legais, constitucionais ou convencionais que devem incidir sobre o caso em exame, "quase como se o operador do direito estivesse num 'supermercado de normas"” (MARTINS; MOREIRA, 2016, p. 313). Ele encontra-se vinculado ao exame das disposições normativas existentes nos ordenamentos internos e internacional, devendo analisar de forma detalhada as consequências da aplicação de cada enunciado normativo e a descrever o raciocínio realizado e justificar as razões que o levaram a adotar determinada solução, conforme aponta Ramos (2016).

Além disso, nada obsta a criação, pelo Estado, de atos normativos mais benéficos aos indivíduos ou grupos em situação de vulnerabilidade, os quais devem prevalecer sobre as disposições convencionais. Não se pode estabelecer, como regra geral, que os dispositivos inscritos nos tratados internacionais são mais favoráveis ao ser humano, na medida em que estes sempre representam padrões mínimos de proteção (AGUILAR CAVALLO; NOGUEIRA ALCALÁ, 2016). Nas palavras de García Ramírez (2014), os dispositivos da Convenção Americana de Direitos humanos são o piso, e não o teto de proteção dos Direitos Humanos.

Dessa forma, estabelece-se um verdadeiro diálogo entre as diversas fontes normativas - nacionais ou convencionais - que integram o sistema de proteção aos direitos humanos, devendo a atuação do intérprete sempre estar direcionada à aplicação dos dispositivos que alcancem, em maior grau, as garantias concedidas aos indivíduos e aos grupos em situação de vulnerabilidade, ou às que limitem em menor extensão tais prerrogativas, independentemente do seu grau hierárquico no ordenamento jurídico (AGUILAR CAVALLO; NOGUEIRA ALCALÁ, 2016, p. 22). 


\section{CONSIDERAÇÕES FINAIS}

A pretensão do presente estudo foi examinar o princípio pro homine e as consequências de sua aplicação para a proteção às vítimas de violação de direitos humanos, sejam elas indivíduos ou grupos em situação de vulnerabilidade, visando à substituição da hierarquia formal proposta por Hans Kelsen pela ideia da primazia da norma mais favorável aos titulares da proteção outorgada pelos ordenamentos jurídicos nacionais e pelos tratados internacionais de direitos humanos.

Para tanto, analisamos inicialmente a estrutura hierárquica proposta na Teoria Pura do Direito, que descreve uma ordem normativa estática, em que cada ato normativo encontra sua posição na pirâmide de acordo com o meio segundo o qual foram criados, servindo as disposições de nível superior como fundamento de validade dos dispositivos hierarquicamente inferiores. Procuramos demonstrar que a ausência de previsão de um lócus específico para os tratados internacionais de direitos humanos não decorrem de omissão, mas sim de uma percepção dos ordenamentos jurídicos nacionais como parte integrante do direito internacional - visão monista com prevalência do direito internacional.

Em seguida, apontamos diversos instrumentos hermenêuticos por meio dos quais se vêm buscando elevar, ao nível constitucional, as disposições inscritas em leis e outros diplomas normativos, especialmente aqueles que dizem respeito à proteção dos direitos fundamentais e dos direitos humanos, de forma a conferir-lhes status privilegiado no ordenamentos jurídicos estatais.

Por derradeiro, examinamos o princípio pro homine, defendendo seu caráter estruturante no Direito Internacional dos Direitos Humanos, decorrente de um esforço conjunto dos Estados em estabelecer um mínimo de proteção aos indivíduos e aos grupos em situação de vulnerabilidade.

Apontamos que a sua aplicação gera consequências de duas espécies. A primeira, de natureza interpretativa, impõe que o operador do Direito atribua aos textos normativos o significado que implique a maior extensão das garantias e prerrogativas por eles fixados em favor da pessoa humana, bem como a adoção de interpretação restritiva quando se estiver diante de situação que implique limitações aos direitos reconhecidos aos sujeitos protegidos. A segunda, de natureza normativa, exige que o julgador, diante de duas ou mais disposições normativas, dê preferência à aplicação daquela que confira a maior proteção aos indivíduos, 
independentemente de sua origem (nacional ou convencional) ou de sua posição hierárquica no ordenamento jurídico.

Os estudos realizados indicam que o princípio pro homine atua como verdadeira bússola, direcionando a atuação do operador do Direito para a aplicação das disposições normativas que melhor realizam a proteção dos direitos humanos, conferindo-lhes primazia a partir da análise de cada caso concreto não se podendo estabelecer, a priori e em abstrato, quais são os dispositivos aplicáveis pelo julgador ou intérprete.

As discussões sobre o princípio pro homine e sobre sua aplicação encontra-se em aberto. Não se trata de um instrumento que afaste, por completo e de forma imediata, todas as considerações a respeito da hierarquia normativa. Por outro lado, não deve ser desconsiderado, em especial no que se refere à proteção e promoção dos direitos conferidos aos indivíduos e aos grupos vulneráveis. Mostra-se indispensável a realização de novos estudos e o aprofundamento do tema, para que esse instituto venha a ser melhor compreendido e mais divulgado, possibilitando sua exploração não apenas pelos doutrinadores, mas principalmente, pelos advogados e pelos membros do Poder Judiciário no julgamento dos casos que são submetidos à sua jurisdição.

\section{REFERÊNCIAS}

AGUILlAR CAVALLO, Gonzalo; NOGUEIRA ALCALÁ, Humberto. El Principio Favor Persona en el Derecho Internacional y en el Derecho Interno como Regla de Interpretación y de Preferencia Normativa. Revista de Derecho Público. Santiago, n.84, 2016. p.13-43. Disponível em: <https://revistas.uchile.cl/index.php/RDPU/article/viewFile/43057/44992>. Acesso em 10 ago. 2017.

ALEXY, Robert. Teoria dos Direitos Fundamentais. 2ed. 4tir. São Paulo: Malheiros, 2015. 669p. [trad. Virgílio Afonso da Silva].

APPIO, Eduardo. Os Juízes e o Controle de Convencionalidade. In: MARINONI, Luiz Guilherme; MAZZUOLI, Valerio de Oliveira (orgs.). Controle de Convencionalidade: Um panorama latino-americano: Brasil, Argentina, Chile, México, Peru, Uruguai. Brasília: Gazeta Jurídica, 2013. p. 181-212

ARGENTINA. Constitución Nacional de la Nación Argentina. Disponível em: $<$ http://www.casarosada.gob.ar/images/stories/constitucion-nacional-argentina.pdf $>$. Acesso em: 10 ago. 2017.

BARROSO, Luís Roberto. Curso de Direito Constitucional Contemporâneo: Os conceitos fundamentais e a construção do novo modelo. 2ed. São Paulo: Saraiva, 2010. 453p. 
BRASIL. Constituição da República Federativa do Brasil. Disponível em: $<$ http://www.planalto.gov.br/ccivil_03/constituicao/constituicaocompilado.htm>. Acesso em: 10 ago. 2017.

Decreto no 591, de 06 de julho de 1992. Atos Internacionais. Pacto Internacional sobre Direitos Econômicos, Sociais e Culturais. Disponível em: <http://www.planalto.gov.br/ccivil_03/decreto/1990-1994/d0591.htm>. Acesso em: 02 jan. 2017.

. Decreto ${ }^{\circ}$ 592, de 06 de julho de 1992. Atos Internacionais. Pacto Internacional sobre Direitos Civis e Políticos. Disponível em: <http://www.planalto.gov.br/ccivil_03/decreto/19901994/d0592.htm>. Acesso em: 02 jan. 2017.

Decreto no 678, de 08 de novembro de 1992. Promulga a Convenção Americana sobre Direitos Humanos (Pacto de São José da Costa Rica), de 22 de novembro de 1969. Disponível em: 〈http://www.planalto.gov.br/ccivil_03/decreto/d0678.htm>. Acesso em: 02 jan. 2017.

Decreto $\mathbf{n}^{\mathbf{0}}$ 7030, de 14 de dezembro de 2009. Promulga a Convenção de Viena sobre o Direito dos Tratados, concluída em 23 de maio de 1969, com reserva aos Artigos 25 e 66. Disponível em: <http://www.planalto.gov.br/ccivil_03/_ato20072010/2009/decreto/d7030.htm>. Acesso em: 10 ago. 2017.

Supremo Tribunal Federal. Recurso Extraordinário no 466343, Tribunal Pleno. Relator: Ministro Cezar Peluso. Brasília, DF, 03 de dezembro de 2008. Diário da Justiça Eletrônico. Brasília, 04 jun. $2009 . \quad$ Disponível $<$ http://redir.stf.jus.br/paginadorpub/paginador.jsp?docTP=AC\&docID=595444 >. Acesso em: 22 maio 2016.

CASTAÑEDA, Mireya. El Principio Pro Persona: Experiencias y expectativas. 2ed. México: Comisión Nacional de los Derechos Humanos, 2015. 315p. Disponível em: 〈http://appweb.cndh.org.mx/biblioteca/archivos/pdfs/lib_PrincipioProPersona2aed.pdf $>$.

Acesso em 10 ago. 2017.

COLÔMBIA. Constitución Política Colombiana. Disponível em: <http://www.corteconstitucional.gov.co/inicio/Constitucion\%20politica\%20de\%20Colombia \%20-\%202015.pdf>. Acesso em 10 ago. 2017.

FAVOREU, Louis; LLORENTE, Francisco Rubio. El Bloque de La Constitucionalidad: Simposium franco-español de Derecho Constitucional. Madrid: Civitas, 1991. 203p.

GARCÍA RAMÍREZ, Sergio. La "Navegación Americana” de los Derechos Humanos: Hacia un ius commune. In: FIX-FIERRO, Héctor Felipe; BOGDANDY, Armin von; MORALES ANTONIAZZI, Mariela (coords.). Ius Constitucionale Commune en América Latina: Rasgos, Potencialidades y desafíos. México: Universidad Nacional Autónoma de México, $2014 . \quad$ p.459-500. Disponível em: <https://archivos.juridicas.unam.mx/www/bjv/libros/8/3655/20.pdf>. Acesso em 04 jan. 2017.

GUASTINI, Riccardo. Interpretare e Argomentare. Milano: Dott. A. Giuffrè, 2011. 453p.

Rev. de Direitos Humanos em Perspectiva | e-ISSN: 2526-0197 | Maranhão | v. 3 | n. 2 | p. 22 - 38| 
guatemala. Constitución Política de la República de Guatemala. Disponível em $\langle$ https://www.oas.org/juridico/mla/sp/gtm/sp_gtm-int-text-const.pdf $>$. Acesso em 10 ago. 2017.

KELSEN, Hans. Teoria Geral do Direito e do Estado. 3ed. 2tir. São Paulo: Martins Fontes, 2000.637p.

Teoria Pura do Direito. 6ed. São Paulo: Martins Fontes, 1998. 428p. [trad. João Baptista Machado].

LAFER, Celso. A Internacionalização dos Direitos Humanos. Barueri: Manole, 2005. 135p.

LOSANO, Mario G.. Sistema e Estrutura no Direito: O Século XX. v.2. São Paulo: WMF Martins Fontes, 2010. 374p. [trad. Luca Lamberti; revisão da tradução: Carlos Alberto Dastoli].

LOURENÇO, Haroldo. Precedente Judicial como Fonte do Direito: Algumas considerações sob a ótica do novo CPC. Revista da AGU. Brasília: vol.11, n. 33, jul./set. 2012, p.241-270. Disponível em: <http://seer.agu.gov.br/index.php/AGU/article/view/107/376>. Acesso em: 10 ago. 2017.

MARTINS, Leonardo; MOREIRA, Thiago Oliveira. Controle de Convencionalidade de Atos do Poder Público: Concorrência ou hierarquia em face do controle de constitucionalidade?. In: PAGILARINI, Alexandre Coutinho; DIMOULIS, Dimitri (Coord.). Direito Constitucional Internacional dos Direitos Humanos. Belo Horizonte: Fórum, 2012. p. 293-315.

MAZZUOLI, Valerio de Oliveira. O Controle Jurisdicional da Convencionalidade das Leis. 4ed. rev., atual. e ampl. São Paulo: Revista dos Tribunais, 2016, 236p. 2010. 251p.

Tratados Internacionais de Direitos Humanos e Direito Interno. São Paulo: Saraiva,

; RIBEIRO, Dilton. The Pro Homine Principle as na Enshrined Feature of International Human Rights Law. The Indonesian Journal of International \& Comparative Law. Jacarta, v.3, n.1, jan. 2016. p.77-99. Disponível em: <https://www.academia.edu/20292282/MAZZUOLI_Valerio_de_Oliveira_RIBEIRO_Dilton. _The_pro_homine_principle_as_an_enshrined_feature_of_international_human_rights_law._I n_Indonesian_Journal_of_International_and_Comparative_Law_vol._III_issue_1_January_2 016_p. 77-99>. Acesso em 10 ago. 2017.

Medellín urquiaga, Ximena. Principio Pro Persona. México: Comisión de Derechos Humanos del Distrito Federal; Suprema Corte de Justicia de la Nación; Oficina en México del Ato Comisionado de las Naciones Unidas para los Derechos Humanos, 2013. 97p. Disponível em:

〈http://www2.scjn.gob.mx/red/coordinacion/archivos_Principio\%20pro\%20persona.pdf>. Acesso em: 10 ago. 2017.

MÉXICO. Constitución Política de los Estados Unidos Mexicanos. Disponível em: <http://www.ordenjuridico.gob.mx/Constitucion/cn16.pdf>. Acesso em: 10 ago. 2017. 
MIRAGEM, Bruno. Eppur si Muove: Diálogo das fontes como método de interpretação sistemática no Direito brasileiro. In: MARQUES, Cláudia Lima (org.). Diálogo das Fontes: Do conflito à coordenação de normas do direito brasileiro. São Paulo: Revista dos Tribunais, 2012. p.67-109.

PERU. Constitución Política del Perú. Disponível em: <http://portal.jne.gob.pe/informacionlegal/Constitucin\%20y\%20Leyes1/CONSTITUCION\%2 OPOLITICA\%20DEL\%20PERU.pdf>. Acesso em 10 ago. 2017.

PINTO, Mónica. El Principio Pro Homine: Criterios de hermenêutica y pautas para la regulación de los derechos humanos. In: ABREGÚ, Martín; COURTIS, Christian. La Aplicación de los Tratados sobre Derechos Humanos por los Tribunales Locales. Buenos Aires: Centro de Estudios Legales y Sociales, 1997, p. 163-172, Disponível em: <http://www.corteidh.or.cr/tablas/20185.pdf> . Acesso em: 10 ago. 2017.

RAMOS, André de Carvalho. Control of Conventionality and the Struggle to Achieve a Definitive Interpretation of Human Rights: The Brazilian experience. Revista IIDH, San José, v.32, n.64, p.11-32, 2016. Disponível em: 〈http://www.corteidh.or.cr/tablas/r36237.pdf $>$. Acesso em: 05 fev. 2017.

Curso de Direitos Humanos. 1ed. 2tir.São Paulo: Saraiva. 2014. 656p.

SAGÜÉS, Néstor Pedro. Obligaciones Internacionales y Control de Convencionalidad. Estudios Constitucionales, Talca, v.8, n.1, 2010, p. 117-135. Disponível em: <http://www.scielo.cl/pdf/estconst/v8n1/art05.pdf $>$. Acesso em 23 dez. 2016.

SARLET, Ingo Wolfgang. A Eficácia dos Direitos Fundamentais: Uma teoria geral dos direitos fundamentais na perspectiva constitucional. 11ed. rev. e atual. Porto Alegre: Livraria do Advogado, 2012. 504p.

Dignidade (da Pessoa) Humana e Direitos Fundamentais na Constituição Federal de 1988. 10ed. rev. atual. e ampl. Porto Alegre: Livraria do Advogado, 2015. 199p.

SCHÄFER, Gilberto. Súmulas Vinculantes: Análise crítica da experiência do Supremo Tribunal Federal. Porto Alegre: Livraria do Advogado, 2012. 184p.

TRINDADE, Antônio Augusto Cançado. O Sistema Interamericano de Direitos Humanos no Limiar do Novo Século: Recomendações para o fortalecimento de seu mecanismo de proteção. In: GOMES, Luiz Flávio; PIOVESAN, Flávia (coord.). O Sistema Interamericano de Proteção dos Direitos Humanos e o Direito Brasileiro. São Paulo: Revista dos Tribunais, 2000. p. 103-179.

URUGUAY. Constitución de la República. Disponível em <https://parlamento.gub.uy/documentosyleyes/constitucion>. Acesso em 10 ago. 2017. 